\title{
De pinos y motosierras: revisión crítica al aprovechamiento forestal comunal en San Jerónimo Coatlán, Oaxaca
}

\author{
Edgar Pérez Ríos \\ Centro de Investigación y Estudios Avanzados del IPN, Ciudad de México, México. \\ Email: edgarperezrios@gmail.com
}

\begin{abstract}
Resumen: El aprovechamiento forestal en México es posible gracias a que, según la Comisión Nacional Forestal (CONAFOR), aproximadamente la tercera parte del territorio nacional está ocupado por superficie forestal arbolada. A través de iniciativas comunales diversos pueblos indígenas han incursionado en el aprovechamiento forestal, mostrando una capacidad de agencia sobre sus recursos maderables. El objetivo de este artículo es analizar la organización e impacto de una de estas iniciativas en el Municipio zapoteco de San Jerónimo Coatlán (MSJC), en la Sierra Sur de Oaxaca, desde una perspectiva etnográfica con apoyo de fuentes documentales locales, además de charlas con comuneros del Municipio. Los principales resultados muestran que a mediados del siglo XX, diversas empresas privadas poseían concesiones para explotar los bosques, pero a finales del siglo se crean comités locales para el aprovechamiento forestal desde la propia comunidad. A partir de entonces se reconfigura la relación entre el bosque/territorio y la comunidad.
\end{abstract}

Palabras clave: Comunalidad, pueblos indígenas, empresa comunal, territorio.

\section{Of pine trees and chainsaws: critical review of communal forestry management in San JeronimoCoatlan, Oaxaca}

Abstract: Forestry exploitation in Mexico is possible because, according to the National Forestry Commission (CONAFOR), approximately one third of the national territory is covered by tree forest area. Through communal initiatives, several indigenous peoples have made their way into forestry, showing agency capacity over their timber resources. The objective of this article is to analyze the organization and impact of one of these initiatives in the Zapotec Municipality of San Jerónimo Coatlán (MSJC), in the Sierra Sur of Oaxaca, from an ethnographic perspective with the support of local documentary sources, as well as talks with community members of the Municipality. The main results show that in the mid-twentieth century, various private companies held concessions to exploit the forests, but at the end of the century local committees were created for forest exploitation from the community itself. From then on, the relationship between the forest/territory and the community is reshaped.

Keywords: Communality, indigenous people, communal company, territory

\section{De pinheiros e motosserras: \\ revisão crítica da silvicultura comunitária em San Jerónimo Coatlán, Oaxaca}

Resumo: O aproveitamento florestal no México é possível, pois cerca de um terço do território nacional é constituído de superfície arborizada (segundo a Comissão Nacional Florestal - CONAFOR). Neste contexto, a agência indígena se revela através de iniciativas comunais de diversos povos voltadas para o aproveitamento florestal, mostrando sua capacidade de agencia sobre o uso dos recursos florestais. O objetivo deste artigo é analisar a organização e impacto de uma destas iniciativas no município zapoteco de San Jerónimo Coatlán (MSJC), na Serra Sul de Oaxaca, a partir de uma perspectiva etnográfica com o apoio de fontes documentais locais e de conversas informais com comuneros do município. Os principais resultados mostram que em meados do século XX, diversas empresas privadas possuíam concessões para explorar os 
bosques, mas no final deste século foram criados comitês locais para o aproveitamento florestal pela própria comunidade. A partir de então, se reconfigura a relação entre a comunidade e o seu território/bosque.

Palavras chave: Comunalidade, povos indígenas, empresa comunitária, território.

\section{Introducción}

El Municipio zapoteco de San Jerónimo Coatlán (MSJC), ubicado en la Sierra Sur de Oaxaca, al sur de México, constituye un vasto territorio de bosques, preponderantemente de pino y encino, pues de sus aproximadamente 558 km2, el 85 \% corresponde a superficie de bosques (INEGI, 2010). Entre las especies más importantes se encuentra el pinus chiapensis, cuya madera suave y de alta calidad "genera una fuerte presión humana para su aprovechamiento comercial” (López, 2007, p. 4).

La capacidad de agencia en el MSJC para decidir sobre sus elementos culturales tangibles y simbólicos históricamente ha estado presente, de tal suerte que la demarcación de su propio territorio -según la historia oral del lugar -deriva de una comisión de hombres que, al momento de la fundación de este pueblo en 1612 (Rojas, 1958), son enviados a marcar los límites del territorio que habría de pertenecerles. Así, establecen sus colindancias hacia el norte con el río Atoyac; hacia el oeste con la región Chatina, hacia el este y parte del sur con otros pueblos zapotecos del Sur y hacia el sur con algunos pueblos costeños.

Durante los siguientes siglos hasta el último tercio del siglo XX, la población del MSJC y sus nuevas comunidades tendrían un control total sobre su territorio y recursos naturales. Pese a la existencia de densos bosques a lo largo y ancho del territorio, solo se utilizaba madera de tamaño menor para el autoconsumo, es decir, para la construcción de viviendas tradicionales conocidas como casas de mayute, las cuales se construyen con barro y varas delgadas, preferentemente de encino. El bosque también procuraba la leña para los braseros o fogones, y algunos terrenos eran rozados ${ }^{1}$ para la siembra de la milpa. El resto del territorio prácticamente se mantenía virgen.

Así pues, la actividad principal del MSJC consistía en la agricultura para el autoconsumo, así como la caza, pues en las serranías abundan venados, jabalíes, ardillas y armadillos, también una diversidad de aves comestibles como palomas, primaveras y gallinitas monteses. La hidrografía del lugar es abundante, por lo que los diversos ríos de la región (Atoyac, Rana, Leche, Tablas, etcétera) también eran y son aprovechados para la pesca de camarones, chacales, cangrejos, ranas y peces. Todo ello constituía una forma de vida sin afectaciones a los recursos naturales maderables.

La organización comunitaria del MSJC con base en la comunalidad (Díaz, 2002; Maldonado 2002; Martínez, 2010), o sea mediante un sistema que considera al territorio, el poder, las fiestas y el trabajo como elementos compartidos entre los distintos miembros de la comunidad, aunado a un sistema de gobierno conocido oficialmente como sistemas normativos internos, ha permitido que sea la propia comunidad la que determine los usos de sus diferentes elementos culturales, entre ellos el territorio. Sin embargo, mediante una decreto a la Ley Forestal de 1940 que permitía concesiones forestales a empresas privadas, a través de Unidades Industriales de Explotación Forestal (UIEF), la empresa Fepatux, dedicada al ramo forestal, logra obtener una concesión para explotar el bosque hasta entonces virgen hacia la década de 1970 (Grupo Mesófilo, 2001).

En las siguientes páginas me interesa analizar cómo ha sido el proceso y el impacto del aprovechamiento forestal, iniciado por la empresa privada Fepatux en 1973, seguida por otras empresas privadas y tomada por la empresa comunal en 1990, aunque con la participación paralela de empresas privadas hasta aproximadamente el 2005. Haré énfasis en este último período, el cual permite ver la agencia de las comunidades por manejar sus propios recursos maderables; las estrategias que utilizan así como una reconfiguración en sus formas tradicionales de relación con el bosque y territorio, pasando así de la agricultura al aprovechamiento forestal. 
Comenzaré entonces exponiendo la metodología que guía esta investigación, así como las herramientas empleadas durante trabajo de campo y proceso de escrituración del artículo. Posteriormente enunciaré los hallazgos encontrados en relación con la agencia de la población del MSJC para el manejo de sus recursos forestales. La discusión la enfocaré particularmente en el impacto que el aprovechamiento forestal ha tenido en la región, impacto a nivel ambiental, ritual y en la cotidianidad de las comunidades del MSJC. Finalmente se ofrecerán algunas reflexiones finales a título personal y como comunero de Las Palmas, San Jerónimo Coatlán, Oaxaca.

\section{Metodología}

Este artículo deriva de un trabajo reflexivo del cual me he ocupado desde hace por los menos diez años. Durante este tiempo he desarrollado lo que desde la antropología se conoce como etnografía, con la intención de allegarme a una descripción densa (Geertz, 1973) sobre los diversos significados que los habitantes del MSJC confieren a los diversos elementos culturales presentes en nuestras comunidades. Me he ayudado también de lo que Rockwell $(1995,2007)$ señala como etnografía histórica, donde las fuentes, archivos y documentos históricos y la propia historia oral permiten comprender dinámicas culturales actuales cuya explicación se encuentra en un proceso de larga data. En ese sentido el presente estaría lleno de huellas del pasado. Este acercamiento etnográfico e histórico lo he fortalecido mediante lo que he denominado lenguaje comunal, es decir, mediante un acercamiento metodológico decolonial enfocado en la co-construcción y compartencia ${ }^{2}$ de conocimientos con otros miembros de la comunidad (Pérez, 2019).

Con la construcción de conocimientos con los miembros de la comunidad me refiero a un proceso reflexivo donde discutimos de manera colegiada algún tema en particular en algún espacio determinado. Así, el tema que aquí me ocupa y los resultados que más adelante se discuten son producto no solo de una reflexión personal sino también de diversas reflexiones conjuntas en distintas asambleas comunales donde los comuneros han manifestado su preocupación por la tala legal e ilegal de nuestros bosques. Esta forma de construcción de conocimientos también se ha desarrollado a través de talleres comunitarios y en espacios casuales como la calle o en alguna fiesta comunitaria.

La compartencia de conocimientos dentro del lenguaje comunal intenta contribuir a perpetuar el carácter colectivo y comunitario de los conocimientos, tal como han sido compartido por nuestros abuelos desde hace siglos e incluso milenios. En ese sentido se contrapone al carácter extractivista que ha caracterizado a las investigaciones académicas, en donde el conocimiento es literalmente apropiado por el investigador, de modo que el conocimiento deja de ser comunal y se convierte en individual bajo amparo de las leyes occidentales, a través de los derechos de la propiedad intelectual, derechos que han contribuido a generar una dicotomía entre el saber comunal y el saber científico:

Las nociones hoy hegemónicas sobre la propiedad intelectual articulan estrechamente, por un lado, la concepción de la superioridad del saber científico/tecnológico occidental sobre toda otra forma de saber y, por el otro, las concepciones liberales del individualismo y de la propiedad privada. En forma consistente con lo que ha sido el orden colonial del sistema-mundo moderno, se define una modalidad de conocimiento (el conocimiento científico/empresarial occidental) como sujeto a la protección de un régimen nacional e internacional de propiedad intelectual, a la vez que se define al conocimiento de los otros como de libre disposición y apropiación (Lander, 2001, p. 79).

Ante ello, la metodología de investigación que guía este trabajo se ha centrado en una co-construcción de conocimientos entre diversos miembros de la comunidad, así como en la compartencia de los mismos en distintos espacios, principalmente las asambleas comunales. Mediante este escrito se pretende abrir nuevos espacios de discusión involucrando a un público más amplio interesado en asuntos y problemáticas que afrontan los pueblos originarios, principalmente en tiempos como este, donde la agencia que tienen las comunidades en relación con su devenir histórico y social está enmarcado por una fuerte presencia de dinámicas socioeconómicas globales. 
Además de la discusión entre distintos miembros de la comunidad, para la elaboración del artículo fueron de mucha importancia los archivos locales, particularmente las actas de asambleas, donde están plasmadas las diversas posturas de los comuneros con respecto a los programas de aprovechamiento forestal que se han desarrollado en nuestras comunidades. Cabe advertir que por decisión comunal dichos documentos no se encuentran referenciados en este artículo, por lo que cualquier persona interesada en el tema podrá recurrir a nuestra asamblea para solicitar permiso de revisar dichos papeles.

Por otra parte, la revisión documental sobre los bosques del MSJC -aunque escasa -permite dimensionar la importancia de este territorio en términos forestales, pues ahí se alberga una cantidad de especies arbóreas y plantas de menor tamaño que ha llamado la atención de al menos un par de investigadores. Así pues, las tesis de Campos (1993) y López (2007) han contribuido a ubicar las especies más importantes de la región. Por su parte el informe de la evaluación rural participativa del Grupo Mesófilo (GM, 2001) realiza un diagnóstico de las condiciones forestales del MSJC así como las estrategias comunales y privadas en cuanto al aprovechamiento forestal. Finalmente, el Plan de Desarrollo Municipal de SJC 2011-2013 brinda una perspectiva del gobierno local en turno relacionado con el aprovechamiento forestal y algunas consecuencias al respecto. ${ }^{3}$

\section{De la caza y la agricultura al aprovechamiento forestal}

Como mencioné en la introducción, los pobladores del MSJC desde la fundación del pueblo en el siglo XVII se dedicaron a la caza, la agricultura y la recolección de yerbas silvestres comestibles. Los abuelos recuerdan que hacia principios del siglo XX y aun hasta 1950, el dinero circulaba con escasa frecuencia entre los pobladores de San Jerónimo Coatlán (SJC) y sus múltiples rancherías dispersas a lo largo y ancho del territorio. En aquellos años el truque $e^{4}$ permitía el acceso a diversos productos, incluso algunos aperos de labranza se conseguían a cambio de café, uno de los productos introducidos en el Municipio para el autoconsumo hacia el primer tercio del siglo pasado y comercializado a mediados del mismo siglo.

El relativo aislamiento en que se encontraban estas comunidades permitía prácticamente una autosuficiencia y autonomía con respecto a casi todas las formas de vida. Incluso en 1900 existía una sola escuela en todo el territorio, ubicada en SJC, la cabecera municipal, donde acudían 35 niños (Rojas, 1962, p. 111), de una población total de 706 habitantes; lo que se explica considerando que la población de SJC era de 184 individuos, mientras que los otros 522 vivían dispersos en sus rancherías (DGE, 1906). Así pues, el control territorial y de los diversos recursos con que se contaban radicaba exclusivamente en el pueblo mediante la asamblea como máxima autoridad municipal. Incluso dicen los abuelos que una pequeña porción del territorio fue dada al Municipio tradicionalmente apicultor de San Gabriel Mixtepec a cambio de cera para la fabricación de velas.

Bajo estas líneas la capacidad de agencia de los pobladores sobre sus elementos culturales tangibles y simbólicos era evidente, pues incluso hacia 1930 cuentan los abuelos que un grupo de comuneros asentados en sus rancherías gestionan la fundación de una nueva comunidad regidos por autoridades propias, pues la cabecera municipal estaba situada a por lo menos un día de camino con respecto a las rancherías, lo que dificultaba cualquier trámite o asunto legal. No sin una serie de dificultades se logra la fundación de Soledad Piedra Larga (SPL) -actual agencia municipal del MSJC -momento en el que los habitantes de esta nueva comunidad se apropian del español como lengua materna, mientras que los habitantes de SJC continuarían hablando di'zhke' (zapoteco del Sur) como primera lengua (Pérez, 2018). Esto resulta relevante pues se tiende a suponer que existe un desplazamiento lingüístico motivado por cuestiones externas a la comunidad, no obstante el caso de SPL demuestra que las comunidades también tienen capacidad de agencia con respecto al devenir de sus lenguas originarias, de ahí que por ejemplo el Municipio vecino de San Vicente Coatlán tiene una población hablante de zapoteco del Sur del 93 \% (INEGI, 2010), mientras que en SPL ya no existe ningún hablante del idioma originario.

El MSJC y sus comunidades tuvieron un manejo y control total de sus recursos hasta 1973, cuando la empresa Fepatux logró obtener una concesión para trabajar los bosques vírgenes del Municipio (GM, 2001). Quienes llegaron a ver los inmensos pinos que taló Fepatux aseguran que estos eran tan gruesos que para rodearlos se necesitaban hasta 10 personas con brazos extendidos; recuerdan que estos eran altísimos llegando 
a medir entre 40 y 50 metros de altura, lo cual no es aventurado considerando que la empresa Fepatux durante los primeros diez años de concesión logró producir anualmente 120 mil m3 de madera de primera clase (Ibid).

De esta manera comenzó en el MSJC una actividad nunca antes vista. Varios comuneros aseguran que en ese entonces ni las autoridades municipales ni comunales tenían mucho conocimiento sobre el impacto de la explotación forestal, de ahí que para los representantes de la empresa no resultó difícil acceder al territorio, sobre todo por el grado de marginación a nivel económico y en los servicios básicos de los cuales la población ha carecido. Así, la ilusión de contar con brechas de terracería que unirían a las distintas rancherías fue uno de los principales alicientes, sin saber que esos caminos eran en sí parte de la infraestructura necesaria para explotar los bosques, extraer la madera y transportarla hacia Tuxtepec, donde se encuentra la papelera dueña de la empresa.

Para la década de 1970 ya se contaba con escuelas tanto en SJC como en SPL y en San Cristóbal Honduras (SCH), otra de las agencias municipales del MSJC. La población había crecido considerablemente pues el Censo General de Población de ese año registró un total de 2540 habitantes. Las relaciones con otros pueblos se hicieron más frecuentes, entre otras razones por la reciente construcción de la carretera estatal 131 que va de Oaxaca a Puerto Escondido, vía Sola de Vega. De esta forma el uso del dinero como valor de cambio también cobró relevancia, por lo que el empleo se convirtió en una necesidad.

La empresa Fepatux encontró en la necesidad de dinero un aliado más a su proyecto, pues en el contexto de la reciente concesión se propusieron decenas de empleos para los comuneros del MSJC. Para la década de 1980 ya había más de cien comuneros empleados en el bosque como cortadores y choferes de camiones madereros. La mayoría de ellos vecinos de SJC, pues los comuneros de SPL para esas fechas trabajaban en la producción de café, cuyos años buenos fueron justo entre 1970 y 1990. Se instaló así una actividad productiva económica que junto con la producción de café desplazaban las actividades tradicionales de agricultura.

A diferencia de otros pueblos zapotecos, sobre todo de la Sierra Norte de Oaxaca, donde diversas organizaciones comunitarias y actores locales hicieron frente a la instalación de empresas madereras privadas, como el caso de San Pablo Macuiltianguis, que en 1967 su población se negó a firmar los contratos de explotación precisamente de la empresa Fepatux, misma que se prolongó durante seis años, hasta que la empresa cedió a algunas peticiones(López, 2007), en el caso de San Jerónimo Coatlán, las autoridades y población en general mantuvieron una actitud pasiva, la cual los mismos comuneros arguyen que se debió a su desconocimiento, a la falta de información y asesoría por parte del gobierno u otras instancias no gubernamentales.

De acuerdo con la cronología propuesta por el GM (2001), Fepatux explotó los bosques de 1973 a 1982, dejando a su filial Etla S.A., quienes continuaron en el territorio hasta 1986. Durante esos 13 años se extrajo la mejor madera de la región y la empresa sin duda vivió una de las etapas más prósperas de su historia. No obstante esa prosperidad, la población del MSJC siguió viviendo en la precariedad, siendo actualmente uno de los municipios con muy alto grado de marginación de acuerdo con los indicadores sociodemográficos de la población indígena (CDI, 2010).

Esta empresa no solo extrajo la mejor madera en rollo de la región sino que también produjo un cuantioso volumen de madera desperdiciada. Así, la madera de tercera y hasta de segunda calidad no fue considerada por la empresa para su comercialización, además de ello diversas especies arbóreas fueron destruidas por el peso de los pinos derribados. Aunque se abrieron brechas de terracería para la transportación de la madera, sus condiciones no eran óptimas, por lo que ocurrieron frecuentes deslaves e incluso accidentes.

Por otra parte, los comuneros denuncian que durante la presencia de la empresa en el MSJC hubo una serie de irregularidades. Para comprender estas irregularidades hay que considerar que el acuerdo entre la empresa y la asamblea fue que un porcentaje de los ingresos por concepto de la venta de madera debía entregarse al Municipio; dicho porcentaje se repartiría de la siguiente manera: $30 \%$ se repartiría entre los comuneros del MSJC y sus distintas comunidades mediante el derecho de monte y el $70 \%$ restante se resguardaría en el llamado fondo común, el cual constituiría un recurso destinado para sufragar diversos gastos del Municipio y 
sus comunidades, como obras públicas, compra de materiales, maquinaria, camionetas de uso comunal, etcétera. Incluso desde entonces se observa una capacidad de agencia en donde la asamblea -quizá desde su desconocimiento sobre el tema -interviene dentro de las actividades forestales.

Pese al acuerdo, las irregularidades que se denuncian es que nunca hubo una información clara y precisa y mucho menos verificada sobre el número de volúmenes efectivamente producidos y vendidos y sobre el ingreso económico real proveniente de la venta de la madera. Cabe apuntar que para la década de 1970 los comuneros afirman que existía un alto grado de analfabetismo, como dijo uno de ellos: "entonces poquitos sabían leer y escribir o hacer cuentas. Como quien dice fácil nos podían engañar”. Aunado al analfabetismo, la casi nula experiencia sobre actividades forestales de las autoridades y los comuneros hacía que el escenario para la empresa fuera el ideal para poder manejar los recursos de acuerdo a sus propios intereses. Sin embargo la asamblea comenzó a inconformarse con el proceder de la empresa, entre otras cosas debido al incumplimiento de varias de sus promesas, como en San Cristóbal Honduras donde habían prometido la introducción de agua potable a la comunidad, lo cual nunca se realizó.

Se puede advertir que la incursión de Fepatux afectó distintas aristas de la vida social del MSJC, como veremos en el siguiente apartado. Aquí vale la pena adelantar que uno de los cambios más profundos producidos como consecuencia de la nueva actividad económica fue la división de la población de SPL, quienes en 1976, a raíz de un desacuerdo en la repartición de un recurso económico por los derechos de monte, comienzan un problema que culminaría en la fundación de la comunidad de Las Palmas, hoy Núcleo Rural, el cual se funda mediante decreto estatal en $1984^{5}$. Así, la inexperiencia en el manejo de recursos económicos por parte de las autoridades derivó en esta y otras problemáticas como la corrupción y el robo. Finalmente la asamblea decide expulsar a la empresa Etla S.A., pero en su lugar se instala la Compañía Forestal de Oaxaca, quienes operaron de 1987 a 1989 y salieron debiéndole dinero al pueblo.

\section{La agencia indígena: creación de la Empresa Comunal Forestal}

La experiencia que se había adquirido a lo largo de las casi dos décadas de actividades forestales y el mal manejo del bosque por parte de las empresas privadas, aunado a “(...) la crisis al interior de las empresas forestales paraestatales y las limitaciones técnicas cada vez más evidentes del régimen de concesiones” (Chapela, 2007, p. 128) motivó en 1990 la creación de la empresa forestal comunal (legalmente conocida como Unidad Económica Especializada de Aprovechamiento Forestal Comunal de San Jerónimo Coatlán), mediante la asesoría de la Secretaría de Desarrollo Agropecuario y Forestal (SEDAF) y la Secretaría de la Reforma Agraria (SRA), misma que en última instancia resultó insuficiente pues la capacitación no fue la adecuada y los manejos de los recursos continuaron bajo las sombras de distintos niveles de corrupción.

La instauración de la empresa comunal en SJC viene precedida de otras experiencias similares en distintas comunidades de Oaxaca gestadas desde la década de 1970, algunas de ellas en la propia Sierra Sur, como el caso de Santiago Textitlán en 1977, además de la cancelación de concesiones en 1983, lo que a su vez influyó para que las comunidades establecieran sus propias empresas comunales (López, 2007). No obstante, a diferencia de las comunidades de la Sierra Norte donde se contó con el apoyo de distintas organizaciones como la Organización para la Defensa de los Recursos Naturales y el Desarrollo Social de la Sierra Juárez (ODRENASIJ) y de intelectuales como Jaime Martínez Luna, originario de la Sierra Juárez, en SJC la organización y defensa de la empresa comunal fue mucho más difícil al contar con escasa asesoría al respecto.

Aunque la empresa forestal comunal comenzó sus operaciones en 1990 con la instalación de un aserradero donado por la SEDAF y coordinado por medio de un comité coordinador nombrado por la propia asamblea de comuneros, distintas empresas privadas continuaron incursionando en los bosques del MSJC, hasta principios de este siglo. Con la empresa comunal se avanzó en cuanto a la agencia que mostró la comunidad en relación con el aprovechamiento de sus recursos forestales, pero con ella continuaron una serie de problemáticas relacionadas con la falta de experiencia en la materia, pues los comuneros desconocían los precios en el 
mercado de la madera, así como la medición de los volúmenes cúbicos de madera, los precios de maquinaria y sobre trámites burocráticos con la Secretaría de Hacienda y Crédito Público (SHCP), lo cual desencadenó una serie de descontentos entre las distintas comunidades pertenecientes al Municipio, sobre todo porque había una concentración de recursos y empleos en la cabecera municipal. Por su parte las autoridades comunales al actuar casi por cuenta propia, es decir muchas veces fuera de la discusión en asamblea, provocaron climas ríspidos que derivaron en la sustitución de los dirigentes.

Bajo este contexto se continuó con el manejo de la empresa forestal comunal hasta octubre de 1997 cuando el huracán Paulina devastó gran parte de la Costa y la Sierra Sur de Oaxaca. Para entonces los volúmenes levantados no pasaban los $20 \mathrm{mil} \mathrm{m} 3$ y las utilidades eran apenas perceptibles por lo que el clima de descontento hacia la empresa comunal seguía en aumento, a lo que los coordinadores aducían que los gastos eran apenas superiores a los costos de producción.

El huracán Paulina de 1997 fue un parteaguas en la organización comunal para el aprovechamiento forestal, pues como consecuencia del fenómeno natural el bosque fue arrasado en gran parte. Cayó un sinfín de árboles de todas clases y tamaños, por lo que la Secretaría de Medio Ambiente y Recursos Naturales (SEMARNAT) concedió permiso a las comunidades para que aprovecharan los árboles caídos, cuyo número era considerablemente alto. Este escenario era ideal para mostrar el descontento hacia la empresa comunal, así que las comunidades (San Cristóbal Honduras, Soledad Piedra Larga, Las Palmas y El Progreso) decidieron organizarse internamente para el corte de madera, organización que perdura en la actualidad mediante un área de corte asignada para cada comunidad. Así, la empresa comunal se descentraliza.

Con esto tenemos una nueva forma de organización comunal para el aprovechamiento forestal, organización que retoma el organigrama de la empresa comunal, de manera que las comunidades mediante la Asamblea comunal nombran comités bajo los siguientes puestos: coordinador, financiero, jefe de monte y documentador, además de que cada comunidad busca a sus propios compradores. Los resultados se muestran alentadores, pues los comuneros observan mayores ingresos, los cuales comienzan a reflejarse en distintas obras públicas, como una iglesia de gran tamaño en SCH y obras en las distintas comunidades. Además, en términos sociales, el aprovechamiento forestal mediante la organización comunitaria ha fortalecido el tejido social en tanto actividad que demanda el diálogo entre comuneros.

Tal como señalan Fuente y Barkin (2011, p. 106) para el caso de la Sierra Norte, la organización comunitaria en las localidades del MSJC, también permitió "el desarrollo de procesos de generación de excedentes con una mayor responsabilidad social y ambiental”, pues como señalé, los recursos económicos se quedaban en las comunidades, se redujo el desperdicio de madera y mediante programas de empleos temporales se llevaron a cabo acciones de reforestación a la vez que los empleos se concentraron en los propios comuneros e incluso jóvenes en edad apta para el trabajo. Así, la agencia indígena se tornó también en una mejor relación con el territorio, ya que incluso previo al comienzo del año se acostumbró la celebración de misas para solicitar la bendición de Dios para un buen trabajo y evitar accidentes.

Pero esta nueva forma de aprovechamiento forestal trae consigo serios problemas a partir del año 2000 cuando los propios comuneros aprenden el oficio de aserrar y sacar tablas, tablones, vigas, etcétera, pues muchos comienzan a comprar motosierras para dedicarse de manera individual e ilegal a la tala y comercialización de la madera. Muchos de ellos se justifican señalando las plagas que afectaron a los cafetales, la principal actividad económica en buena parte del territorio hasta antes del huracán, el cual los orilló a buscar nuevas fuentes de empleo, encontrando en el bosque no solo un empleo sino también una fuente muy redituable económicamente. Así, en la actualidad funcionan los comités de aprovechamiento forestal de manera paralela con los aserradores clandestinos, cuyos volúmenes extraídos muchas veces superan a lo propio hecho por la comunidad, de manera que como sostiene Varese (2011, p. 107).

Aquellos campesinos indígenas que, a través de la torturada historia agraria del continente, pudieron mantener una relación de continuidad con sus tierras y sus territorios fueron adaptando su sistema de conocimientos y sus prácticas de uso ambiental -sus relaciones con la 'naturaleza'-a las nuevas circunstancias de la economía política del mercado capitalista. 


\section{La relación hombre-tierra en tiempos del capitalismo}

Actualmente los pobladores del MSJC y sus comunidades han recuperado el control total sobre el aprovechamiento forestal. Las empresas privadas fueron expulsadas definitivamente en la década del año 2000, pero su paso en nuestras comunidades fue más devastador que el propio huracán Paulina. Los comuneros reconocen que hasta hace poco "hemos empezado a despertar"; hoy en día cualquier persona extraña en nuestras comunidades es observada con desconfianza. Hace poco una empresa constructora solicitó permiso para extraer arena y grava del río Rana en Las Palmas, pero la asamblea de comuneros se lo negó rotundamente. Los propios investigadores que esporádicamente han visitado la Sierra Sur de Oaxaca también son vistos con desconfianza.

Pero las empresas madereras dejaron una profunda huella en la comunidad: divisiones, pleitos y la herencia de explotar los bosques, pues actualmente las actividades forestales ocupan el primer lugar en cuanto a actividades productivas en el Municipio. Sin embargo, la explotación forestal no se ha traducido en una mejor calidad de vida para los habitantes del MSJC, por el contrario se puede observar una disparidad en los ingresos de las familias: solo unas cuantas familias han acumulado un importante capital económico pero el $62 \%$ de la población vive en pobreza extrema, el nivel de pobreza más alto en México de acuerdo con el Consejo Nacional de Evaluación de la Política de Desarrollo Social (CONEVAL, 2010).

$\mathrm{Al}$ respecto varios abuelos comentan que antes todos eran iguales, todos se dedicaban a sembrar su milpa. Efectivamente hasta antes de la explotación forestal la población del MSJC mantenía una relación bastante estrecha con la tierra sobre todo a través de la ritualidad (Pérez, en prensa). En el caso del cultivo del café no se observa grandes cambios ya que los comuneros afirman haberse dedicada al cultivo del café y sus actividades agrícolas al mismo tiempo. Pero en otras comunidades zapotecas del Sur, donde se produjo café a una escala mayor sí se observa un cambio en la ritualidad indígena, pues el monocultivo de café:

(...) ha impactado de manera sustancial diversos ámbitos de la vida social, entre ellos la ritualidad en general y la de carácter agrícola en específico (...) Debido a ello, en las parcelas de ambas comunidades [en la región de Loxicha] dejaron de realizarse los rituales agrícolas que tradicionalmente marcaban los ciclos agrícolas y ritual. (González, 2016, p. 188-189).

Para el caso del MSJC, como decía, la relación con el territorio se daba mediante la ritualidad. Prácticamente todas las familias originarias del territorio tenían por costumbre solicitar permiso a la tierra antes de sembrar el maíz y antes de recoger las cosechas. Uno de los abuelos recuerda cómo se realizaban estos rituales.

Pues tempranito, antes de que amanezca uno se tiene que bañar bien limpio. Se tiene que ir a bañar al río y ponerse ropa limpia. Luego ya cuando uno llega al cerro donde está el rozo, entonces ahí uno debe llevar su luz y su copal. Deben ponerse siete luces en el centro del terreno y el humo de copal se hace a los cuatro puntos cardinales. Entonces mientras se echa el humo se dice el rezo. El rezo dice: "vengo a dejar aquí esta luz al Señor para pedirle que cuide nuestra siembra, que espante a cualquier animal dañero que quiera comerse el maíz”. Se le pide permiso a la tierra, a Dios, para que uno pueda sembrar.

El mismo abuelo cuenta que cuando los primeros elotes están listos para cortarse tiene lugar una segunda ceremonia:

Cuando se van a cortar los primeros elotes también se tiene uno que bañar bien temprano en el río y de ahí subir al cerro para cortar los elotes. Tiene uno que llevar copal. Se tienen que escoger tres elotes, esos elotes se tienen que bendecir con el humo de copal y asarlos. Cuando ya se asaron los elotes otra vez se les echa humo de copal y entonces nomás uno tiene que comerse los tres elotes aunque haya dos o más personas. Ya entonces se le da gracias a Dios y uno puede entonces cortar los elotes y llevárselos a la casa para comer.

Incluso se cuentan historias relacionadas con el rayo, entidad considerada como la máxima deidad entre los pueblos zapotecos del Sur. Así, el rayo no solo es dador de la lluvia y de la fertilidad, sino que también es el 
dueño de los varios animales del bosque como el venado. Cuidar de la tierra y de los animales se consideraba un deber de la gente, pues no hacerlo tenía sus consecuencias como se puede apreciar en el siguiente relato proveniente de la historia oral de nuestras comunidades:

Dicen que hace mucho tiempo vivía un señor allá por El Encanto, allá tenía su ranchito. Ese señor se dedicaba a cazar venados. También sembraba su maíz y con eso se mantenía. Pero un día que andaba matando venados se le apareció el rayo ${ }^{6}$ y le dijo: ¿por qué andas matando mi ganado? Ahora te voy a llevar a mi casa y te vamos a comer. Esos venados son míos y ya no quiero que los estés matando. Entonces el rayo se lo llevó a su cueva. El señor nomás lloraba y le pedía perdón al rayo, le decía que ya no iba a matar más venados. En eso estaban cuando llegaron los hijos del rayo, pero el rayo grande escondió al señor para que no lo vieron los rayos pequeños. Pero los hijos del rayo lo ventearon y le dijeron al rayo grande "aquí huele a gente, hay que comérnoslo". Entonces el rayo mayor les explicó a sus hijos sobre la historia de ese señor y les dijo que el señor estaba muy arrepentido y que ya no iba a matar más venados. Al final logró convencer a los rayos pequeños para que no se lo comieran, pero con la condición de que iban a tener al señor un tiempo ahí con ellos para vigilarlo y ver si de verdad estaba arrepentido. Entonces ahí estuvo el señor con los rayos, iban a sembrar maíz y aunque el señor veía a los venados no intentaba matarlos, así que después de un tiempo dijo el rayo mayor: este señor ya está listo para regresar a su casa y como ha demostrado que ya cambió, le vamos a ayudar. Mira -le dijo al señor -ten este bule, ahí hay mucha neblina; ahora te vas a dedicar a cosechar frutas y verduras. Para que riegues tus plantas solo tienes que abrir el bule para que llueva sobre tus tierras. Así le dijo y entonces el señor pudo regresar a su casa y desde entonces se dedicó a cosechar frutas y verduras. Dicen que entonces ese señor bajaba desde El Encanto y venía a estas rancherías a vender sus productos. Así fue como dejó de matar los venados.7

La relación entre el hombre y la tierra estaba mediada principalmente por el rayo, de ahí que se trataba de una relación armoniosa, ya por el temor a ser castigados, ya por la espiritualidad que le profesaban. Pero con la apertura de nuestras comunidades por medio de las carreteras también se hicieron presente nuevas religiones, sobre todo evangélicas, las cuales criticaron con dureza las tradiciones de los habitantes del MSJC; les predicaron por años y lograron introducir nuevas formas de comprender el mundo. De esta forma se conformarían dos grandes grupos que pueden observarse hasta la actualidad: los de creencias (mena yint) y los que no son de creencias (mena xtil). Los primeros han preservado de alguna u otra manera su ritualidad prehispánica, mientras los segundos han adoptado una mirada más de carácter global y son, en general, quienes con mayor fuerza han incursionado en actividades de explotación forestal.

Las personas de creencias se refieren al rayo -actualmente representado en piedras conocidas como guardamontes -con un profundo respeto. En este sentido, al guardamonte se le atribuyen ciertas cualidades benefactoras, como las que nos menciona un comunero: "cuando íbamos a campiar con mi papá, primero pasábamos a ver al guardamonte. Se le pedía la bendición para que nos cayera un venadito. Y sí, seguro que nos caía uno o a veces hasta dos". Otro comunero más joven comentó: "hace poco fuimos a campiar. Fui yo y otro señor. El señor pasó a dejarle unos adornos al guardamonte y a pedirle que nos cayera el venado”.

El guardamonte también tiene que ver con la adopción de una conducta apropiada cuando se acude al cerro para trabajar. He escuchado al menos seis o siete testimonios de personas que fueron "castigados" por el guardamonte debido a conductas inapropiadas, por lo regular enojo o flojera. Alguien comentó que estando arando la tierra con sus bueyes, sucedió que éstos andaban muy aprisa y que destruían los surcos, lo cual suscitó la ira del campesino, quien comenzó a golpear y maldecir a su ganado. Por la tarde, al llegar a su casa se encontró con que tenía una fuerte calentura y dolor de cabeza. Consultó a "alguien que da razón” para ver qué es lo que tenía. Fue ahí donde descubrió que el guardamonte se había apoderado de él debido a su conducta. Como remedio le recetaron acudir al guardamonte para pedirle perdón; tenía que llevar copal para quemar al pie de la piedra, así como una vela. Después de realizar esta ceremonia fue liberado.

Otra persona confesó haber desafiado al guardamonte. Yendo hacia su trabajo vio un guardamonte en la loma del cerro y como no había nadie en el lugar ni iba acompañado decidió tomar la piedra y arrojarla por la barranca. Después se dirigió a su trabajo y al caer la tarde regresó a su casa. Una vez en su casa comenzó a sentir 
una fuerte calentura y dolor de cabeza, por lo que también acudió al que da razón y éste le dijo lo mismo que al campesino del arado, sin embargo, en su caso tuvo que recoger la piedra y volver a colocarla en su sitio. Tras realizar la misma encomienda pudo aliviarse.

Alguien más arrancó un guardamonte y se lo llevó para su casa para ponerlo “de lujo” en su patio. Así lo hizo, pero durante las noches aseguró tener pesadillas y sueños muy feos, pero no se deshacía de la piedra. La gente le decía que el guardamonte no lo iba a dejar en paz y así fue, pasaban los días y esta persona seguía teniendo sueños horribles, hasta que un día decidió ir a dejar el guardamonte al sitio de donde lo tomó. Finalmente cesaron sus tormentos.

Si bien la ritualidad prehispánica fue desplazándose con el cambio en las actividades productivas, también es cierto que con la instauración de comités para el aprovechamiento forestal, esta ritualidad se re-configuró mediante un sincretismo religioso, de modo que año tras año los comités organizan la celebración de misas en el bosque previo al comienzo de cada año de trabajo, lo cual de alguna manera preserva la relación de respeto hacia la Madre Tierra, situación que no se observa en las actividades de los taladores clandestinos. Quizá esto se deba a que los puestos de Comité regularmente pertenecen a personas originarias de lugar, mientras que muchos taladores ilegales son personas avecinadas hace relativamente poco tiempo.

Así, la cosmovisión en torno al rayo como dador de la fertilidad y como patrón del pueblo ha sido desplazada con fuerza en las últimas décadas. Actualmente solo los abuelos y algunos pocos adultos de mediana edad conocen la ritualidad y muy pocos la conservan en la práctica. Como dijo Carlos Marx, el dios dinero se ha instalado en las subjetividades de los individuos del MSJC, como se ha instalado en diversos pueblos indígenas:

De forma creciente los otros factores de la economía capitalista se fueron instalando en la mentalidad y acción social indígena, en sus culturas adaptadas, de tal modo que nociones de 'propiedad privada' empezaron a entrar en conflicto con la tradición de 'los comunes', el individualismo con la solidaridad, el interés y la ganancia con la reciprocidad, la diversidad de manejo y producción con la especialización de mercado y el monocultivo. (Varese, 2011, p. 107)

Dicha situación no es exclusiva del MSJC, sino que son consecuencia de una política de Estado deliberadamente neoliberal a partir de 1992, cuando el gobierno de Carlos Salinas de Gortari promulgó reformas institucionales y agrarias, dando paso a la obtención de títulos de propiedad privada de parcelas individuales, siendo que antes de dicho año las tierras comunales eran inalienables Wilshusen (2007), y por tanto, se sometían a decisiones de la Asamblea. El mismo autor refiere a la desintegración de dos ejidos forestales en Quintana Roo en 1997, cuyo resultado fue la organización en grupos pequeños, los cuales:

(...) no invirtieron beneficios provenientes de la madera en equipo u otros bienes colectivos sino que retuvieron el dinero para el uso personal o familiar [...] Es un hecho que los grupos se formaron para que algunos jefes de familia pudieran manejar directamente los ingresos provenientes de la madera (Wilshusen, 2007, p. 207).

De este modo la relación entre el hombre y la tierra ya no está mediada por el rayo, sino por el Mercado, ahora el dinero es el motor que impulsa a los comuneros a internarse en el bosque, motosierra en mano, espoleados por el deseo y necesidad de dinero. En las asambleas de comuneros se ha tocado muchas veces el tema de la deforestación, pero los taladores clandestinos no asisten. Su respuesta ante el cuestionamiento de sus actividades ilícitas siempre es la misma: “¿ustedes nos van a mantener?” Las autoridades también están sobrepasadas o han caído en la corrupción y ésta a su vez en la impunidad.

El aprovechamiento forestal aparece aquí como explotación forestal. Sin embargo muchos jóvenes que poco a poco hemos tenido acceso a la educación superior e incluso a posgrados hemos llamado la atención sobre este asunto. La propia realidad de las comunidades también invitan a pensar: los ríos cada vez más estrechos y la lluvia cada vez menos intensa son una clara muestra de los efectos de la deforestación. Los comités comunales de aprovechamiento forestal han comenzado a tomar cartas en el asunto mediante progra- 
mas de reforestación y empleo temporales. Varias zonas del territorio están siendo re-pobladas por especies de pinos, pero el problema se mantiene en los taladores clandestinos, cuyos ingresos no se retribuyen de ninguna forma en el bienestar de la comunidad.

La asamblea dice que el problema no está tanto en que se aprovechen los recursos forestales del bosque sino en la forma en que se está haciendo. La acción más inmediata en que todos convergemos tiene que ver con la regulación de la tala, es decir, con el cese a la tala clandestina. Este es el principal problema que afronta nuestras comunidades. Basta darse una vuelta por Las Palmas, Piedra Larga, Honduras, Progreso, El Mirador, San Jerónimo o por las brechas de terracería que conectan a los diversos pueblos del Municipio para ver cómo por todas partes hay tablas, tablones o vigas esperando comprador o esperando el camión que los transportará principalmente para Puerto Escondido, en donde las cabañas de los extranjeros están a la espera de construirse con la hermosa madera de los bosques de la Sierra Sur.

\section{Reflexiones finales}

Quienes tenemos menos de 40 años hemos crecido viendo pasar los camiones madereros que bajaban de la Sierra dirigiéndose a Oaxaca o a Puerto Escondido a dejar grandes volúmenes de madera. Quienes fuimos niños en la década de 1990 nos tocó ver camiones trayendo a cuestas bolos de madera tan grandes que con menos de diez piezas se cubría toda la superficie del camión. Crecimos jugando en el aserrín y jugando con pedacitos de madera que hacían las veces de carros, casas o personas, pero no sabíamos lo que todo eso significaba.

Quienes en el año 2000 teníamos 12 o 13 años de edad recordamos a los famosos rajeros, gente blanca proveniente del estado de Jalisco que obtuvo uno de los últimos permisos para extraer madera de nuestros cerros. Los recordamos porque en nuestra comunidad, Las Palmas, instalaron su campamento y ahí trasladabas los restos de los árboles destruidos por el huracán; a esa edad tan solo veíamos el polvadero de los camiones nos alistábamos para ayudar a descargar y ganarnos diez pesos para tomarnos un refresco y comprar golosinas. Veíamos con asombro la llegada de los tráiler a la comunidad para transportar las rajas de madera a quién sabe dónde.

Luego cuando fuimos más grandes muchas veces preferimos dejar la secundaria para formar parte de las filas de los acarreadores de madera. Fuimos de las primeras generaciones de adolescentes que buena parte del tiempo estuvimos en el cerro trabajando como trabajan quienes tienen más de cinco hijos qué mantener. Vimos a nuestros padres trabajar en el bosque; nos íbamos semanas completas a sacar tablas, a arrastrarlas, fregándonos literalmente el lomo. En tono de chascarrillo nos dicen que nosotros nos quedamos chaparros por tanta madera que cargaron nuestros hombros.

¡Pero nos sentíamos libres!

Finalmente algunos preferimos el camino de la escuela, no sin múltiples obstáculos por nuestra condición de pobres e indígenas. Otros prefirieron quedarse en el bosque, pasaron de acarreadores de madera a aserradores, luego que fueron más grandes compraron sus motosierras y comenzaron a trabajar por su cuenta. El bosque deja, el bosque da dinero. Al tiempo compraron sus camionetas de tres toneladas, las mejores para transportar la madera. Salieron adelante. Algunos me preguntaban ¿para qué tanto estudio? No sin razón, a la misma edad ellos tenían automóviles propios, yo apenas lograba juntar el dinero suficiente para pagar mis pasajes desde la Ciudad de México a mi pueblo, retirado a unas 12 horas de la capital.

Sí. Históricamente hemos tenido capacidad de agencia sobre nuestro devenir histórico como pueblo originario. Pero también nos ha alcanzado el contexto global. Desde el siglo V se tuvo la agencia para formarnos como pueblos zapotecos del Sur (Gay, 1881), expulsando quizá injustamente a los chontales de aquellas serranías donde actualmente vivimos. En el siglo XVI nuestro pueblo Coatlán fue unos de los que más ferozmente resistieron a la conquista española, incluso causando temor en el ejército invasor y sus aliados (Barabás, 1989; González, 2011; Roulet, 2008). Tras una resistencia finalmente fallida se optó por otra estrategia, la 
apropiación cultural (Bonfil, 1991), la cual dio pie a la desintegración de Coatlán y la fundación de diversos pueblos hoy conocidos como coatlanes, donde está San Jerónimo Coatlán.

Toda esta historia de lucha y resistencia parece contrastar con lo que sucede actualmente, pues en varias aristas de la vida social se ha dejado la lucha comunal y se han emprendido proyectos individuales. En ese sentido nuestras comunidades parecen un pequeño espejo de la sociedad global, de aquella sociedad que tanto se nos da criticar.

Para nada estas palabras deben leerse de manera romántica o como un canto al pasado. Como sociedades todos los pueblos estamos en un constante cambio. Lo aquí escrito más bien debería leerse de manera crítica y profunda. Tenemos el derecho a nuestra libre determinación, pero las comunidades tenemos la obligación de educarnos en la libre determinación, considero que ese es el reto pendiente para que nuestra capacidad de agencia se torne en posibilidades de mejorar nuestras condiciones de vida y relación con los demás.

\section{Notas}

\footnotetext{
${ }^{1} \mathrm{El}$ rozo es una actividad que consiste en preparar un terreno para la siembra. Se cortan los arbustos y árboles grandes, de manera que el terreno quede totalmente despejado para sembrar.

${ }^{2}$ Martínez (2010) propone el concepto de compartencia en contraste con competencia, entendiendo esta como una lógica económica capitalista, mientras aquella responde a una naturaleza colectiva. Para nuestro tema, los saberes son colectivos y la compartencia es la forma en cómo se socializan.

${ }^{3}$ Remito a los lectores interesados en aspectos técnicos del aprovechamiento forestal en el MSCJ a GM (2001), donde se detalla más al respecto, pues en este artículo se abordan más bien aspectos sociales en torno al aprovechamiento forestal, particularmente el papel de los comuneros en dichas actividades.

${ }^{4}$ Sistema de intercambio de productos sin la intermediación del dinero.

${ }^{5}$ Decreto 139 de la Quincuagésima Primera Legislatura del Estado, publicado en el Periódico Oficial del Gobierno Constitucional del Estado Libre y Soberano de Oaxaca, Tomo LXVI, Alcance al núm. 12. 22 de Marzo de 1984. P. 43.

${ }^{6}$ Entre los zapotecos del Sur se considera al rayo como dueño de ciertos animales como el venado, la culebra y el xumbil. Actualmente aún se le pide permiso para la caza del venado.

${ }^{7}$ Otras versiones similares a esta historia en distintos pueblos zapotecos del Sur se encuentran documentadas en Beam (2013) y González (2012).
}

\section{Bibliografía}

Barabás, A. (1989). Utopías indias. Movimientos sociorreligiosos en México. Ciudad de México:México: Grijalbo.

Beam, R. (2013). El hombre que conoció a Cocijo. Tlalocan (19) 93-223. Recuperado de https://revistasfilologicas.unam.mx/tlalocan/index.php/tl/article/view/228/227

Bonfil, G. (1991). La teoría del control cultural en el estudio de procesos étnicos. Estudios sobre las culturas contemporáneas, 6 (12), 165-204.

Campos, D. (1993). Estudio florístico de la porción central de Municipio de San Jerónimo Coatlán (Oaxaca) (Tesis de licenciatura). Universidad Nacional Autónoma de México, Ciudad de México. México.

CDI. (2010). Indicadores sociodemográficos de la población total y la población indígena por Municipio. San Jerónimo Coatlán. Recuperado de http://www.cdi.gob.mx/cedulas/2000/OAXA/20159-00.pdf

Chapela, F. (2007). El manejo forestal comunitario indígena en la Sierra de Juárez, Oaxaca En D. Bray, L. Merino y D. Barry (ed.), Los bosques comunitarios de México. Manejo sustentable de paisajes forestales (pp. 123- 
146). México, D.F: SEMARNAT/UNAM

CONEVAL. (2010). Informe anual sobre la situación de pobreza y rezago social. San Jerónimo Coatlán, Oaxaca. Recuperado de https://www.gob.mx/cms/uploads/attachment/file/34493/Oaxaca_159.pdf

DGE. (1906). División territorial de la República mexicana formada con los datos del Censo de 1900. Recuperado de http://www.beta.inegi.org.mx/app/biblioteca/ficha.html?upc=702825010018

Díaz, F. (2002). Autonomía y comunalidad india. Enfoques-propuestas. Oaxaca, México: INAH.

Fuente, M. y Barkin, D. (2011). Concesiones forestales, exclusión y sustentabilidad. Lecciones desde las comunidades de la Sierra Norte de Oaxaca. Desacatos (37). 93-110. Recuperado de http://www.scielo.org.mx/pdf/ desacatos/n37/n37a7.pdf

Gay, J.A. (1881). Historia de Oaxaca.Ciudad de México,México: Imprenta del Comercia de Dublan y C.

Geertz, C. (1973). The interpretation of cultures.New York, USA: Basic Books, Inc.

GM (2001). Informe de la evaluación rural participativa efectuada en la comunidad agraria de San Jerónimo Coatlán. Grupo Mesófilo A.C. Recuperado de http://www.grupomesofilo.org/pdf/proyectos/ERP/ ERP_coatlan.pdf

González, D. (2016). De cocijo al rayo. Acercamiento etnohistórico a la ritualidad agrícola de los zapotecos del Sur de Oaxaca. Itinerarios (24). 187-214. Recuperado de http://itinerarios.uw.edu.pl/wp-content/uploads/ 2016/12/I-10-perez-popr-lekki-1.pdf

(2012). Introducción del café en Oaxaca según documentos de Archivo del Poder Ejecutivo del Estado. El caso de Santiago Xanica. Relaciones (130), 131-154.

(2011). Gente belicosa. Resistencia indígena en la Sierra Sur de Oaxaca: Coatlán 1524-1547. En: F. Castro(Presidencia), Congreso Internacional de etnohistoria americana. Problemas del pasado americano. Congreso realizado por el Instituto Nacional de Antropología e Historia, Taxco, Guerrero, México.

INEGI. (2010). Censo de Población y Vivienda. Principales resultados por localidad (ITER). Recuperado de

Lander, E. (2001). Los derechos de la propiedad intelectual en la geopolítica del saber de la sociedad global del conocimiento. Comentario internacional (2) 1-28. Recuperado de https:/www.tni.org/files/ Derechos\%20de\%20\%20propiedad\%20intelectual\%20y\%20geopol\%C3\%ADtica\%20del\%20conocimiento.pdf

López, G. (2007). Estructura y distribución espacial de un bosque de Pinus chiapensis en la Sierra Sur de Oaxaca (Tesis de maestría). Colegio de Postgraduados. Texcoco, México.

López, R. (2007). El empoderamiento del manejo forestal comunitario en Oaxaca. La Unión de Comunidades Forestales y Ejidos de Oaxaca 1985-1996. En D. Bray, L. Merino y D. Barry (ed.), Los bosques comunitarios de México. Manejo sustentable de paisajes forestales (pp. 147-162). México, D.F: SEMARNAT/UNAM

Maldonado, B. (2002). Autonomía y comunalidad india. Enfoques y propuestas desde Oaxaca. Oaxaca, México: Centro INAH, Secretaría de Asuntos Indígenas del Gobierno del Estado, CEMPIO.

Martínez, J. (2010). Eso que llaman comunalidad. Oaxaca, México: Culturas Populares, CONACULTA, Secretaría de Cultura, Fundación Alfredo Harp Helú.

Pérez E. (2019). El lenguaje comunal como aproximación metodológica decolonial. Avá. Revista de antropología (33). 
Pérez E. (en prensa). Gué sant. Continuidad religiosa prehispánica entre los zapotecos del Sur. Itinerarios (29).

Pérez E. (2018). ¿Desplazamiento o apropiación lingüística? La castilla en el proceso fundacional de dos comunidades zapotecas del Sur de Oaxaca. En: A. Civera (Presidencia), IV Coloquio de estudiantes de doctorado. Avances y perspectivas en la investigación educativa. Coloquio organizado por el Departamento de Investigaciones Educativas del CINVESTAV, Ciudad de México, México.

Rockwell, E. (2007). Huellas del pasado en las culturas escolares. Revista de antropología social (16), 175-212.

(1995). De huellas, bardas y veredas: una historia cotidiana en la escuela. En: Rockwell, E. (coord.), La escuela cotidiana (pp. 13-57). Ciudad de México, México: Fondo de Cultura Económica.

Rojas, B. (1962). Miahuatlán, un pueblo de México. Monografía del Distrito de Miahuatlán, Oaxaca. Vol. II.Oaxaca, México: Papeles de Oaxaca

(1958). Miahuatlán, un pueblo de México. Monografía del Distrito de Miahuatlán, Oaxaca. Vol. I.Oaxaca, México: Papeles de Oaxaca

Roulet, E. (2008). Los caciques de Coatlán frente al cristianismo (Nueva España 1544-1547). Recuperado de http://www.ajlas.org/v2006/paper/2008vol21no104.pdf

Varese, E. (2011). El dilema antropocéntrico. Notas sobre la economía política de la naturaleza en la cultura indígena. Quaderns de L'Institut Català d'Antropologia (27), 97-122. Recuperado de https://www.raco.cat/ index.php/QuadernsICA/article/view/258372/351474

Wilshusen, P. (2007). ¿Adaptación o fracaso colectivo? El surgimiento de "grupos de trabajo" en dos ejidos forestales en Quintana Roo, México. En D. Bray, L. Merino y D. Barry (ed.), Los bosques comunitarios de México. Manejo sustentable de paisajes forestales (pp. 195-229). México, D.F: SEMARNAT/UNAM 